\title{
USE OF PLASTIC WASTES AND RECLAIMED ASPHALT FOR SUSTAINABLE DEVELOPMENT
}

\author{
UMAR HAYAT $^{1^{*}}$, ABDUR RAHIM ${ }^{2}$, AMMAD HASSAN KHAN ${ }^{3}$, \\ ZIA UR REHMAN ${ }^{4}$ \\ ${ }^{1-4}$ Dept of Transportation Engineering and Management, \\ University of Engineering and Technology, Lahore, Pakistan
}

Received 25 September 2019; accepted 19 February 2020

\begin{abstract}
The increased cost of virgin material, declining resources and increasing plastic wastes have turned the research momentum towards sustainable and green pavements. Reclaimed Asphalt Pavement (RAP) from the construction industry and plastic wastes disposal is the main problem for Pakistan as well as other developing countries in the face of fewer funds for the construction, repair, and rehabilitation of the extensive road network. In this research, the attempt has been made to study the use of Reclaimed Asphalt Pavement and plastic wastes to counter these issues. Virgin binder was modified with three different contents $(2 \%, 4 \%$, and $6 \%)$ of Polyethylene Terephthalate and three contents $(20 \%, 30 \%$, and $40 \%)$ of Reclaimed Asphalt Pavement. Conventional properties of the modified binder were determined by penetration and softening point. At the same time, thermal stability was checked by Thermal Gravimetric Analysis, and resistance against rutting was evaluated with the help of Dynamic Shear Rheometer. It is observed that modified binder remains stable up to a temperature of $470{ }^{\circ} \mathrm{C}$ and showed improved resistance
\end{abstract}

* Corresponding author. E-mail: 2017mste15@student.uet.edu.pk

Umar HAYAT (ORCID 0000-0003-1231-611X)

Abdur RAHIM (ORCID 0000-0001-6124-0444)

Ammad Hassan KHAN (ORCID 0000-0003-0767-3032)

Zia ur REHMAN (ORCID 0000-0001-7637-1113)

Copyright (C) 2020 The Author(s). Published by RTU Press

This is an Open Access article distributed under the terms of the Creative Commons Attribution License (http://creativecommons.org/licenses/by/4.0/), which permits unrestricted use,

distribution, and reproduction in any medium, provided the original author and source are credited. 
against rutting. Marshall mix properties were determined and compared to specifications of the National Highway Authority of Pakistan. Optimum Marshall stability was observed with 4\% Polyethylene Terephthalate, and 30\% Reclaimed Asphalt Pavement, while flow and air voids remained in limits. As per the results, utilisation of plastic wastes in asphalt pavements-enhances the performance and helps to reduce the environmental pollution and landfill problems due to Reclaimed Asphalt Pavement and plastic wastes.

Keywords: asphalt rheology, binder modification, Marshall stability and flow, plastic, Polyethylene Terephthalate (PET), Reclaimed Asphalt Pavement (RAP), sustainability, Thermal Gravimetric Analysis (TGA), waste materials.

\section{Introduction}

The cost of virgin materials has significantly increased recently, and there are declining resources for road construction. The highway agencies cannot afford to waste material, which is recyclable and reclaimed to construct sustainable infrastructure. There is also an increasing trend to use additives or conjugating materials, i.e. crumb rubber, foundry sands, coal combustion products, and plastic wastes to improve the volumetric properties of asphalt mixture.

Because of economic development and population growth, Pakistan has built a broad network of flexible roads, including the China-Pakistan Economic Corridor and rural roads. A significant portion of the existing roads have deteriorated or is completing service life. Conventionally, deteriorated asphalt layers have been scarified and dumped as waste in Pakistan. On the other hand, Recycled Asphalt Pavement (RAP) is being used for pavements rehabilitation all across the globe. This work has focused on the evaluation of the Marshall volumetric properties of reclaimed asphalt mixtures by the addition of plastic wastes. The primary thrust of the research is focused on the popular and rheological properties of the bitumen binder modified with RAP asphalt and Polyethylene Terephthalate (PET) and their chemical compatibility.

The overlay of asphalt over the deteriorated asphalt layer is a basic procedure to restore serviceability of roads. The main issue with asphalt overlaying is the nature of road material after passing some time and traffic, cracks and distresses of underneath layer re-surface on the newly laid asphalt layer. Also, at this point, the inquiry remains on how to manage the removed materials. The options are either to discard or reclaim it for pavement construction; thus, the utilisation of RAP emerged with guaranteed numerous monetary and environmental advantages.

The first time RAP was utilised in asphalt mixes was in the early 70s with $3 \%$ addition to the virgin binder in asphalt blend, from that 
point onward, due to the increase in expense of binder, higher per cent were permitted. This percentage has increased up to $30 \%$ and even half (Hansen \& Copeland, 2015). Federal Highway Administration estimates that approximately 30 million tons RAP is annually reused, sparing citizens more than the 277.53 Eur (\$300) million every year by decreasing material and transfer costs (Centre for Environmental Excellence..., 2011). In Europe, RAP utilisation is about 0.84, 7.30, 0.53 and around 0.12 million tons in Sweden, Germany, Denmark and Netherlands, respectively (Holtz \& Eighmy, 2000).

The network that has completed its design life is going to undergo maintenance by new techniques. Many state organisations have additional detailed critical reserve funds at the point when RAP is utilised (Page \& Murphy, 1987). The reuse of road materials is suitable for a few reasons, principally to protect the natural resource, and to fulfil financial necessities by diminishing the expense of the development and restoration. In this regard, American asphalt plants in 2012 utilised an expected 68.3 million tons of RAP for the production of new asphalt pavements (Copeland, 2011). Furthermore, for the utilisation of RAP for roads and subbase application, investigation demonstrated that RAP is useful for road construction. There are no significant concerns associated with utilising unbound RAP (Hoppe, Lane, Fitch, \& Shetty, 2015). Besides, Locander (2009) found that utilising RAP, as unbound aggregates is a reasonable option. From the tests, it was concluded that RAP has higher stiffness than an unbound customary utilised base and somewhat higher penetrability.

Recycled Asphalt Pavement, generally, delivered from surface courses (contrasted with binder) is of lesser quality because of the high-quality material utilised in the first development (Saeed, 2008). Thus, there is a need to improve its binder properties. The standard technique to improve and modify properties of asphalt is to modify it with different polymers and additives, self-healing agents, air blowing and addition of diluent oils (Becker Yvonne, Mendez, \& Yajaira, 2001). Virgin polymers have been used to improve attributes asphalt pavements for a long time. Also, there has been an increasing trend for the swap of virgin material by reused wastes, for example, PET wastes. The addition of crumb rubber obtained from waste tires has shown outcomes in asphalt (Kuloglu, 1999).

Plastic is a non-biodegradable material, and it has been analysed that it stays for a long time without degradation. The use of plastic worldwide is growing tremendously, from 204 million tons in 2002 to about 300 million tons in 2013 (PlasticsEurope, 2013). Similarly, around 40 million tons of solid waste are produced annually in India and are continually growing at a pace of $1.5 \%$ to $2 \%$. Plastics comprise to 
around $12.3 \%$ weight of the complete solid waste. The more significant part of the plastics portion is drinking bottles that mainly contain PET (Ramadevi \& Manju, 2012). The plastic bottles contain 55\% to 60\% PET. In developed countries, Hong Kong, United States, Japan, Germany and the United Kingdom have a convincing plastic waste collection network. The top dealers of the world, including China 5.6 Eur (\$6.1) billion), Hong Kong 1.52 Eur (\$1.65) billion, followed by United States, Netherlands, and Belgium, use recycled plastics for closed-loop reuse in jugs (11\%), sheets (49\%), strings (34\%), and various products (6\%) (Velis, 2014).

The recycled PET helps to overcome asphalt rutting and expands the opposition of the material to temperature changes. The plastic recycling studies are limited; nevertheless, plastic benefits have been demonstrated in altered blends when contrasted with the regular blends (Hamid, Hassan, \& Shams, 2008). Kalantar, Karim, \& Abdel Aziz (2011) also explored the option of using plastic wastes in asphalt. The characteristics of the PET binder acquired by the temperature of fixed mixing were examined. Asphalt binder has been modified with PET in $2 \%, 4 \%, 6 \%, 8 \%$, and $10 \%$ (by weight of optimum asphalt) with asphalt penetration grade 80-100. Because of their greater and their softening point that compared to a traditional binder, it is construed that PET modified binder gives better resistance against permanent deformation. Also, utilising PET modified binder adds towards the consumption of plastic waste, thus safeguarding the environmental (Rahman \& Wahab, 2013). Modified asphalt mixtures with reused PET mixture focus varies from $5 \%$ to $25 \%$ of the asphalt binder weight. The results obtained from the experiments reveal the extreme continuous disfigurement of modified asphalt blend happened at a replacement of $20 \%$ with reused PET. In comparison to unmodified asphalt mixture, the resistance of PET modified asphalt mixtures generally improves. The findings show that PET enhances the asphalt mixture volumetric characteristics. There are no considerable adverse effects detected while recycling and during the working life of PET modified asphalt pavements regarding toxic fume generation or hazardous leachate (White, 2019). The Polyethylene Terephthalate-modified asphalt combination is considered ecologically and effectively suitable for pavements (Rahman \& Wahab, 2013).

Moreover, Rasool, Fahad, \& Awaeed (2015) utilised PET to examine the likelihood of using waste plastic bottles as polymer added substances in the bituminous mixture to overcome asphalt pavement issues. The percentages included five distinct extents of PET in 2\%, 4\%, $6 \%, 8 \%$, and $10 \%$ by weight of asphalt. It was demonstrated that the material modified with 8\% PET (plastic bottles) is a suitable proportion to use. In the study of Mahendra, Kumar, \& Prasad (2016), different properties of aggregate, asphalt and asphalt blend were examined by
Use of Plastic

Wastes and

Reclaimed Asphalt for Sustainable

Development 
including different percentages, i.e. at $0,2 \%, 4 \%, 6 \%$, and $8 \%$ by weight of asphalt. The significant enhancements were found in these blends due to the addition of PET waste.

The desirable performance of asphalt mixture, furthermore, include; decreasing its cracking, producing stiffer mixes at high temperatures and reducing rutting and consistency. Thus, expanding pavement dependability, quality of blends, enhancing wearing resistance of mixes, oxidation resistance, decreasing thickness and life expenses of asphalts (Lewandowski, 1994). The Polyethylene Terephthalate waste is also added to the asphalt mix in a dry procedure, for example, utilised in the asphalt blend to enhance the resistance against permanent deformation and Marshall Stability as demonstrated in various studies (Ahmadinia, Zargar, Karim, Abdelaziz, \& Shafigh, 2011; Moghaddam, Soltani, \& Karim, 2014).

In regards to the RAP, the percentage is generally added at $20 \%$ to $25 \%$, as different research articles have demonstrated that excessive content of RAP is not suitable. It was concluded that PET modified asphalt improves the stability of the mix. Polyethylene Terephthalate waste utilisation possibility derived through the mixing of additives to improve the performance of asphalt mix blends containing a high level of RAP binder assessed (Leng, Sreeram, Padhan, \& Tan, 2018). The outcomes showed that the samples containing RAP and PET wastes improved their properties and shown identical behaviour to deal with two locally available wastes reclaiming.

In summary, an innovative way is to utilise waste plastic in asphalt mixture containing RAP, which is likewise a material construction waste. This research aims to individually evaluate the addition of waste plastic materials PET and RAP into asphalt pavement for improvement in asphalt mixtures.

\section{Methodology}

The Recycled Asphalt Pavement samples were obtained from Thokar Niaz Baig to Hudyiara Drain section of the national highway "N-5" of Pakistan. The collected RAP has completed his design life as an overlay was laid ten years before this section. Aggregate and binder were separated with the help of the extraction machine by using trichloroethylene. Penetration test was carried out to determine RAP binder grade and found 48 (40-50 grade). Because of RAP penetration grade, the virgin binder grade was chosen as one grade more (60-70) than RAP binder. The test methodology is presented in Figure 1. 


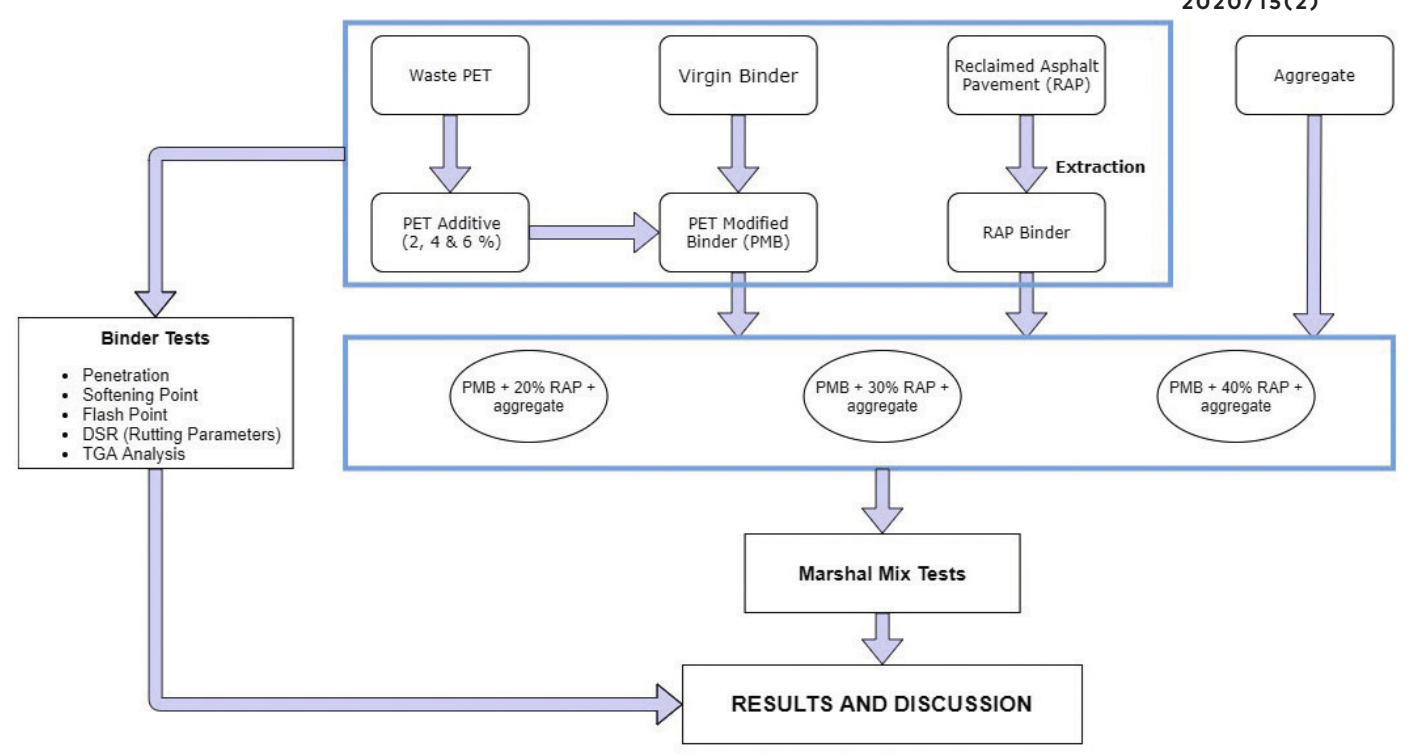

Figure 1. Research methodology

Polyethylene Terephthalate was obtained from plastic wastes bottle. These bottles were crushed into small pieces of $5 \mathrm{~mm}$ by $5 \mathrm{~mm}$ (Figure 2) pieces with the help of crushing machine and kept in the oven for 3 hours at $250{ }^{\circ} \mathrm{C}$ (melting point of PET). Polyethylene Terephthalate was then mixed in shear mixer at $170 \mathrm{rpm}$ with the virgin binder. The virgin binder was blended with three different percentages of PET as given in Table 1. This Polymer Modified Binder (PMB) blended with three different content levels $(20 \%, 30 \%$, and $40 \%)$ of RAP binder

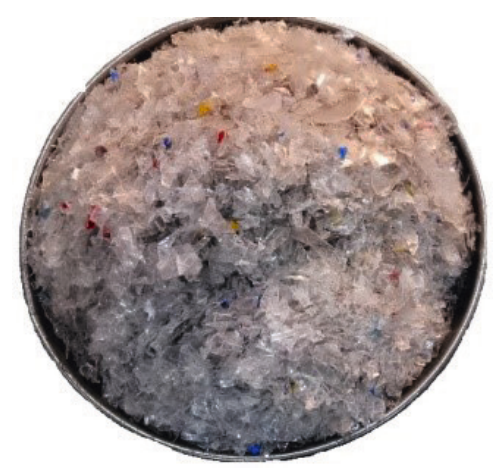

Figure 2. Shredded plastic wastes 
Table 1. Content of Polyethylene Terephthalate and virgin binder in Polymer Modified Binder

\begin{tabular}{ccc}
\hline \multirow{2}{*}{ Sample ID } & \multicolumn{2}{c}{ Content } \\
\cline { 2 - 3 } & $\begin{array}{c}\text { Binder, } \\
\%\end{array}$ & $\begin{array}{c}\text { Polyethylene Terephthalate, } \\
\%\end{array}$ \\
\hline A & 98 & 2 \\
B & 96 & 4 \\
C & 94 & 6 \\
\hline
\end{tabular}

with the help of a shear mixer. Conventional, rheological and Thermal Gravimetric Analysis (TGA) was conducted to determine the properties and behaviour of modified binder.

For this research study, one type of aggregate and virgin binder with RAP and PET has been evaluated, which is the limitation of this study. Asphalt Marshall mix (18 specimens) with three different percentages of RAP and PET (Table 2) were prepared at $4.6 \%$ predetermined optimum binder content. The specimens were prepared as per American Association of State Highway and Transportation Officials (AASHTO) R68 Standard Practice for Preparation of Asphalt Mixtures by Means of the Marshall Apparatus and 75 number of blows applied on each face of the sample, which replicated the traffic condition of heavy vehicles of the national highway. After sample preparation, Marshall testing was performed to determine the volumetric properties and strength parameters of the asphalt mix.

Table 2. Content of Polymer Modified Binder and Recycled Asphalt Pavement binder in modified asphalt mix

\begin{tabular}{ccc}
\hline Sample ID & Recycled Asphalt Pavement, \% & Polymer Modified Binder \\
\hline P2R2O & 20 & $80 \%$ of A \\
P2R30 & 20 & $80 \%$ of B \\
P2R4O & 20 & $80 \%$ of C \\
P3R2O & 30 & $70 \%$ of A \\
P3R30 & 30 & $70 \%$ of B \\
P3R4O & 30 & $70 \%$ of C \\
P4R2O & 40 & $60 \%$ of A \\
P4R30 & 40 & $60 \%$ of B \\
P4R4O & 40 & $60 \%$ of C \\
\hline
\end{tabular}

Note: $A, B$ and $C$ is the content of PET modified binder derived from Table 1. 


\section{Results and discussion}

\subsection{Conventional properties of the binder}

A penetration test ASTM D5/D5M - 19a Standard Test Method for Penetration of Bituminous Materials, a commonly used technique, was carried out to assess the consistency of bituminous material and its penetration grade (Figure 3). The results show that the penetration in general decreases with increasing the content of PET (plastic wastes). The penetration values of PET are comparable to that of the virgin binder; however, the RAP binder is less stiff, possibly due to residue of the cleaning agents.

For the construction of road, before the mixing of the bituminous binder with aggregates binder must be soft enough to mix correctly and wet the aggregates and help to increase the laying of asphalt mix. The ring and ball softening point test ASTM D36/D36M - 14e1 Standard Test Method for Softening Point of Bitumen (Ring-and-Ball Apparatus) were performed to assess the softening point (Figure 4). The softening point temperature of the modified binder has slightly reduced. However, the values are significantly higher than that of the RAP binder. It is consistent in the discussion from the literature that unmodified RAP residue binder is not feasible for road construction. It means that PET modified binder might be less susceptible to temperature changes. Its use with virgin binder and PET permitted as far as popular properties are concerned. By using plastic modified binders, resistance against rutting increases due to high softening temperatures. However, the results indicate the inefficacy of the conventional binder tests for quality control without evaluation of more fundamental material properties of binder and overall performance of asphalt mixture.

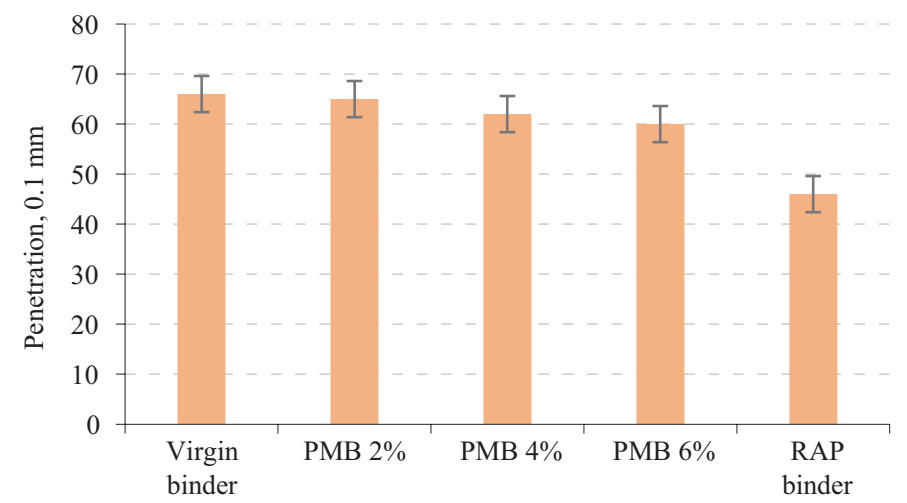

Figure 3. Penetration against Polymer Modified binder and virgin binder
Use of Plastic

Wastes and

Reclaimed Asphalt for Sustainable

Development 


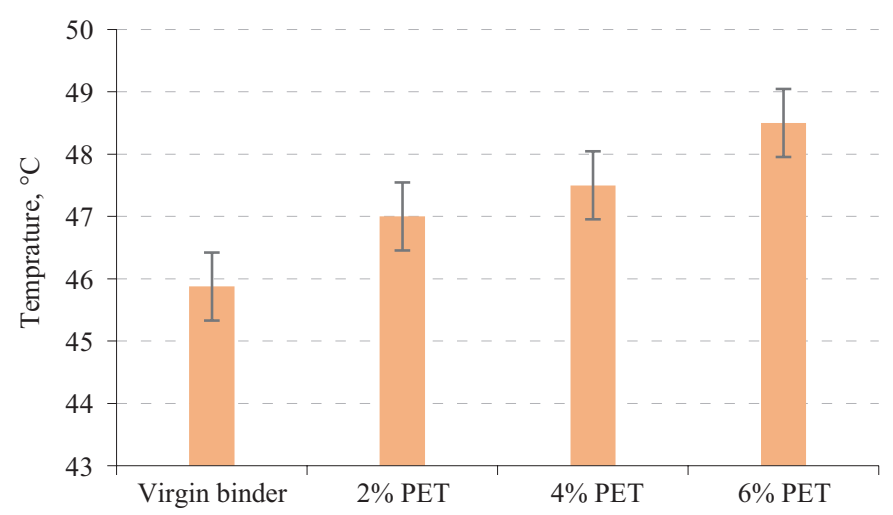

Figure 4. Softening point temperature against Polymer Modified binder and virgin binder

\subsection{Recycled Asphalt Pavement rheology}

The test of the Dynamic Shear Rheometer was carried out to quantify the viscous and elastic behaviour of asphalt binder at intermediate temperature. Unaged binder samples were tested at five temperatures $\left(58^{\circ} \mathrm{C}, 64^{\circ} \mathrm{C}, 70^{\circ} \mathrm{C}, 76^{\circ} \mathrm{C}\right.$, and $82^{\circ} \mathrm{C}$ ) by using $25 \mathrm{~mm}$ diameter spindle, while the frequency of spindle kept $10 \mathrm{rad} / \mathrm{sec}$. The behaviours of the material are analysed by evaluating the complex shear modulus $\left(G^{*}\right)$ and phase angle. $G^{*}$ is considered to be the total resistance of the sample to deformation when repeatedly sheared. On the other hand, phase angle $(\delta)$ is the lag in responses of material against applied shear stress.

By using the above determinations, rutting and fatigue cracking potential has been determined. The value of $G^{*} / \sin \delta$ is the parameter strongly correlated with permanent deformation (rutting) of bituminous pavements in the specification of Superpave. It is observed from Figure 5 that with the increasing percentage of RAP and PET in the binder, $G^{*} / \sin \delta$ value increase. A bituminous binder that is resistant to rutting needs to be stiff enough to avoid large deformations and elastic enough to return to the original form after removing the load. Therefore, $G^{*} / \sin \delta$, the elastic part of the complex shear modulus shows that the resistance of the asphalt to rutting rises with the addition of PET in asphalt.

Rutting is usually a significant concern during the early and midlife of pavements; this is why a minimum threshold is specified for the elastic component of the complex shear modulus. Binders with a high $G^{*}$ value are stiffer, which makes them more resistive against deformation and those with a low $\delta$ value have a high elastic part of $G^{*}$, which makes them 


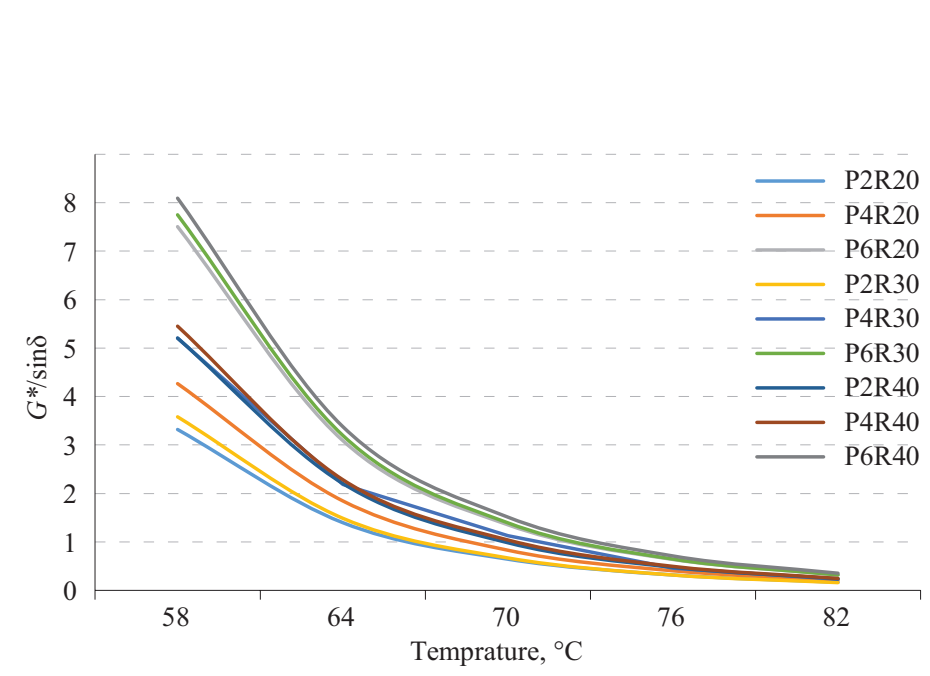

Figure 5. Rutting parameter against different temperatures

more flexible and elastic. Additionally, PET increases the asphalt binder high-performance temperature; i.e. modified blends passes the $G^{*} / \sin \delta$ requirement of Superpave at higher temperatures.

\subsection{Thermal Gravimetric Analysis}

The temperature at which decomposition occur in modified binder must be above the asphalt laying temperature. The test of the TGA was carried out on eight samples with three content of PET $(2 \%, 4 \%$, and $6 \%)$ to determine the decomposition temperature of PMB. Thermal decomposition was verified by using $4 \mathrm{mg}$ sample under nitrogen atmosphere (flow $30 \mathrm{ml} / \mathrm{min}$ ) for a temperature range of $35^{\circ} \mathrm{C}$ to $600{ }^{\circ} \mathrm{C}$ at the heating range of $20^{\circ} \mathrm{C} / \mathrm{min}$.

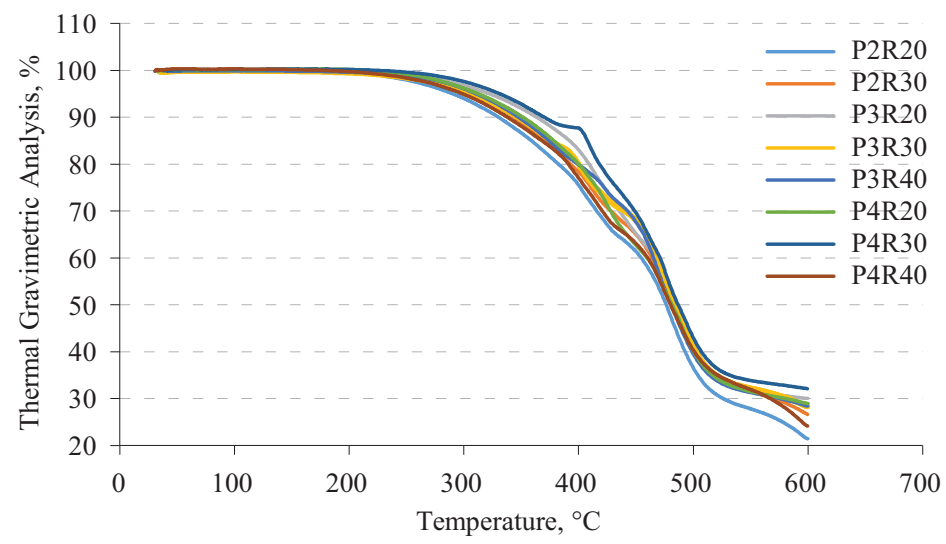

Figure 6. A mass loss at different temperature 
Figure 6 shows that dramatic mass loss occurs at two stages. The onset temperature for the modified binder is $210{ }^{\circ} \mathrm{C}$ after that mass loss occurring gradually. From the above figure, it is observed the PMB maintains thermal stability up to a temperature of $470{ }^{\circ} \mathrm{C}$, beyond this temperature $\mathrm{PMB}$, starts to degrade significantly with a maximum mass loss rate at $500^{\circ} \mathrm{C}$.

\subsection{Marshall stability and flow}

Figure 7 shows the results of Marshall stability of three different contents of PET and RAP. The sample with 2\% PET and 20\% RAP does not meet the minimum criteria of $1000 \mathrm{~kg}$ Marshall stability of National Highway Authority (NHA). The Marshall stability value increases by adding waste PET into asphalt mixtures up to $4 \%$ plastic. However, at high plastic contents, Marshall stability decreases. Reduction in stability with the increase of PET content is attributed to the decrease in the adhesion between aggregate and asphalt. The sample with 4\% PET and $30 \%$ RAP has the maximum Marshall stability.

Marshall flow values for various mixtures are shown in Figure 8. These values are indicative of the flexibility of asphalt mix against the repetitive load. The Marshall flow criterion defined by NHA is $8-14 \%$. It is observed that as the PET content increases, the flow of the mix decreases. It appears that adding PET to the mix has a remarkable effect in decreasing the flow of the mix, but all samples are in the specified limit. The flow of binder with 6\% PET is in prescribed limits. However, the Marshall stability of binder having 4\% PET is maximum, by considering this aspect, it is concluded that binder modified with $4 \%$ PET and 30\% RAP shows optimum results.

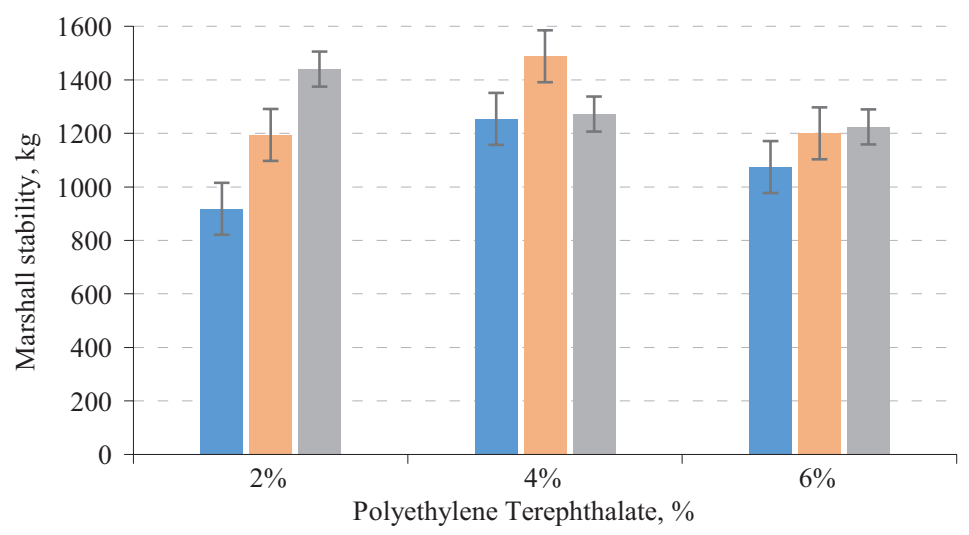

Figure 7. Marshall stability of modified asphalt mixes 


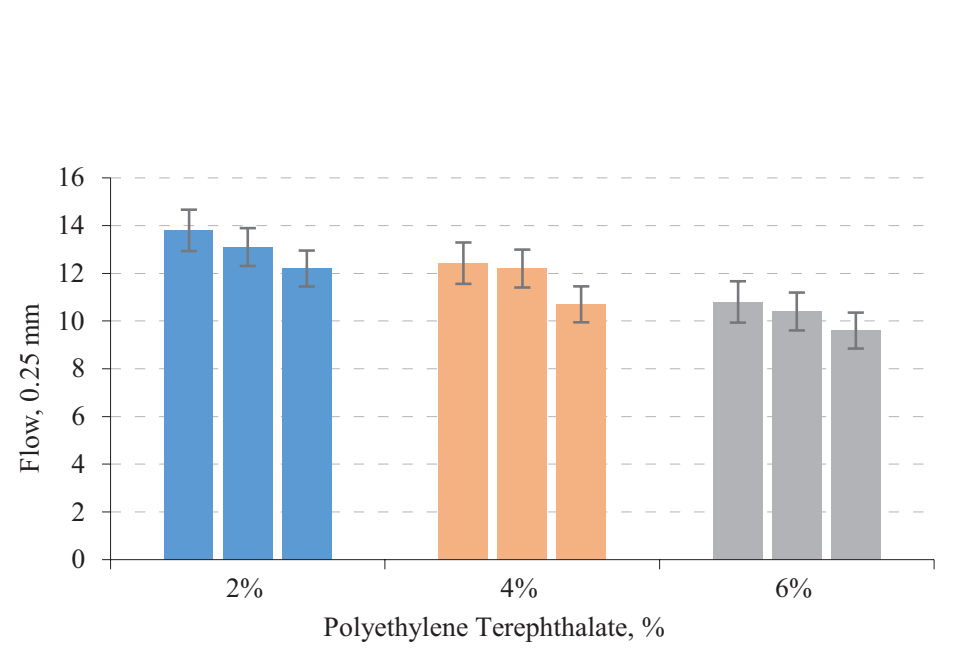

Figure 8. The flow of modified asphalt mixes

\subsection{Voids in mix}

The bituminous durability has a relationship with the voids in the mix (VIM) or porosity. As Figure 9 shows, at 2\% PET and 20\% RAP, there is higher porosity, which provides a path for the entrance of air and water in the asphalt mixture. A PET 4\% and 30\% RAP, porosity (void) is low, which means that more durable is the mix. The low porosity leads to the flow of excess asphalt from the asphalt mixture to the surface of pavement that is why Asphalt Institute established criteria for voids in the mix, for traffic of heavy vehicles, which is 3-5 per cent. Therefore, the air voids in the mix low enough to be durable and impermeable and high enough to prevent the asphalt pumping under the action of traffic and high temperature. From below Figure 9, it observed that with 4\% PET and $30 \%$ RAP content air voids are in permissible limits as suggested by Asphalt Institute.

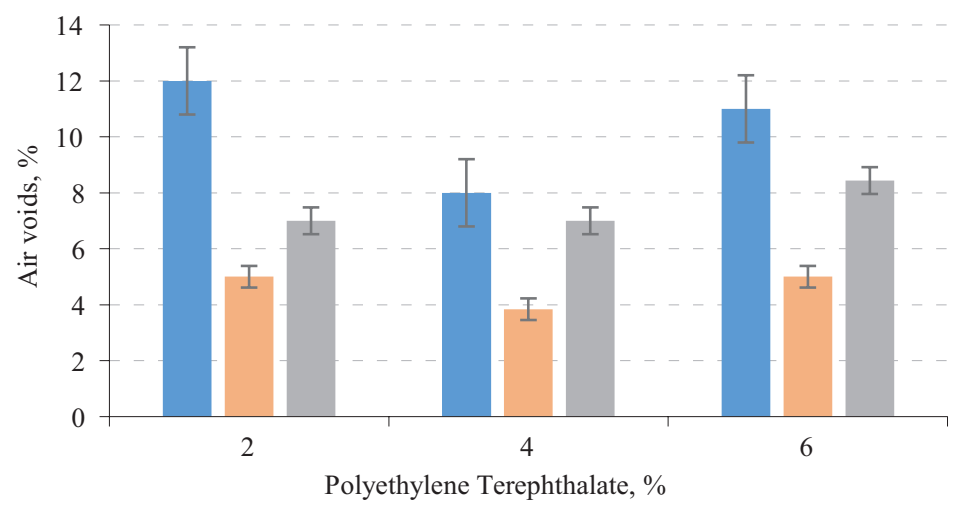

Figure 9. Air voids against modified binder 
Figure 9 shows that increase in PET content cause decrease in voids until a certain point and adding more PET shows opposite results. After a certain amount of PET, the contact point between aggregates decreases, and the PET absorb the asphalt that the mix needs to fill the voids between aggregates.

\section{Conclusions}

Based on the above discussion leads to the following conclusion:

1. Plastic wastes Polyethylene Terephthalate is a useful additive in asphalt mix to improve its mix performance.

2. Adding plastic waste Polyethylene Terephthalate has a significant effect on asphalt binder volumetric characteristics, and it increases the resistance against permanent deformation. Dynamic Shear Rheometer findings also indicate that the Recycled Asphalt Pavement and Polyethylene Terephthalate modified binder increases the resistance against rutting at intermediate to high temperatures.

3. Maximum stability achieved by adding $4 \%$ Polyethylene Terephthalate and 30\% Recycled Asphalt Pavement.

4. Plastic wastes Polyethylene Terephthalate and Recycled Asphalt Pavement binder in asphalt mix significantly reduce the construction cost and environmental pollution.

It is concluded that the asphalt mix prepared with $4 \%$ Polyethylene Terephthalate and 30\% Recycled Asphalt Pavement binder is useful for road construction. The use of non-biodegradable plastic is also a costeffective and easy way of disposal, leading to sustainability in road construction. It is recommended there is further need to evaluate the complex behaviour of binder modified with Recycled Asphalt Pavement and Polyethylene Terephthalate for permanent deformation, fatigue and lower temperature cracking.

\section{REFERENCES}

Ahmadinia, E., Zargar, M., Karim, M. R., Abdelaziz, M., \& Shafigh, P. (2011). Using waste plastic bottles as additive for stone mastic asphalt. Materials \& Design, 32(10), 4844-4849. https://doi.org/10.1016/j.matdes.2011.06.016 American Association of State Highway and Transportation Officials (AASHTO) R68

Standard Practice for Preparation of Asphalt Mixtures by Means of the Marshall Apparatus

ASTM D36 / D36M - 14e1 Standard Test Method for Softening Point of Bitumen (Ring-and-Ball Apparatus) 
ASTM D5/D5M - 19a Standard Test Method for Penetration of Bituminous Materials

Becker Yvonne, Mendez, M., P., \& Yajaira, R. (2001). Polymer modified asphalt. Vision Technology, 9(1), 39-49.

Centre for Environmental Excellence by AASHTO (2011). State-of-the-Practice Report: Source Control

Copeland, A. (2011). Reclaimed asphalt pavement in asphalt mixtures: State of the practice (No. FHWA-HRT-11-021). United States. Federal Highway Administration. Office of Research, Development, and Technology.

Hamid, B., Hassan, Z., \& Shams, N. (2008). The use of polymer modification of bitumen for Durant hot asphalt mixtures. Journal of Applied Sciences Research, 4(1), 96-102.

Hansen, K. R., \& Copeland, A. (2015). Asphalt pavement industry survey on recycled materials and warm-mix asphalt usage: 2014 (No. Information Series 138).

Holtz, K., \& Eighmy, T. T. (2000). Scanning European advances in the use of recycled materials in highway construction. Public Roads, 64(1).

Hoppe, E. J., Lane, D. S., Fitch, G. M., \& Shetty, S. (2015). Feasibility of reclaimed asphalt pavement (RAP) use as road base and subbase material (No. VCTIR 15-R6). Virginia Center for Transportation Innovation and Research.

Kalantar, Z., Karim, M. R., \& Abdel Aziz, M. (2011). Effect of the waste plastic bottles on properties of asphalt. In: Proceedings of the Eastern Asia Society for Transportation Studies, 20-23 Jun 2011, Jeju, Korea.

Kuloglu, N. (1999). Effect of astragalus on characteristics of asphalt concrete. Journal of Materials in Civil Engineering, 11(4), 283-286.

https://doi.org/10.1061/(ASCE)0899-1561(1999)11:4(283)

Lewandowski, L. H. (1994). Polymer modification of paving asphalt binders. Rubber Chemistry and Technology, 67(3), 447-480.

https://doi.org/10.5254/1.3538685

Leng, Z., Sreeram, A., Padhan, R. K., \& Tan, Z. (2018). Value-added application of waste PET based additives in bituminous mixtures containing high percentage of reclaimed asphalt pavement (RAP). Journal of Cleaner Production, 196, 615-625.

Locander, R. (2009). Analysis of using reclaimed asphalt pavement (RAP) as a base course material (No. CDOT-2009-5). Colorado Department of Transportation, DTD Applied Research and Innovation Branch.

Mahendra, S. P., Kumar, N. S., \& Prasad, K. V. R. (2016). Improvement in the properties of bituminous pavements using recycled pet waste materials. A National Conference on Fifteen Years of PMGSY.

Moghaddam, T. B., Soltani, M., \& Karim, M. R. (2014). Evaluation of permanent deformation characteristics of unmodified and Polyethylene Terephthalate modified asphalt mixtures using dynamic creep test. Materials \& Design, 53, 317-324. https://doi.org/10.1016/j.matdes.2013.07.015

Okafor, F. O. (2010). Performance of recycled asphalt pavement as coarse aggregate in concrete. Leonardo Electronic Journal of Practices and Technologies, 17(9), 47-58.

Page, G. C., \& Murphy, K. H. (1987). Hot-mix recycling saves Florida D0T \$38 million. Asphalt, 1(1). 
PlasticsEurope (2013). Plastics - the facts 2013. An Analysis of European latest plastics production, demand and waste data, Plastic Europe; Brussels

Rahman, W. M. N. W. A., \& Wahab, A. F. A. (2013). Green pavement using recycled polyethylene terephthalate (PET) as partial fine aggregate replacement in modified asphalt. Procedia Engineering, 53, 124-128.

https://doi.org/10.1016/j.proeng.2013.02.018

Ramadevi, K., \& Manju, R. (2012). Experimental investigation on the properties of concrete with plastic PET (bottle) fibres as fine aggregates. International journal of emerging technology and advanced engineering, 2(6), 42-46.

Rasool, D. A., Fahad, B. M., \& Awaeed, K. M. (2015). Utilisation of Waste Plastic Water Bottle as a Modifier for Asphalt mixture Properties. Journal of Engineering and Sustainable Development, 19(2), 89-108.

Saeed, A. (2008). Performance-related tests of recycled aggregates for use in unbound pavement layers (No. Project 4-31). https://doi.org/10.17226/23108

Velis, C.A. (2014). Global recycling markets - plastic waste: A story for one player - China. Report prepared by FUELogy and formatted by D-waste on behalf of International Solid Waste Association - Globalisation and Waste Management Task Force. ISWA, Vienna, September 2014.

White, G. (2019). Evaluating recycled waste plastic modification and extension of bituminous binder for asphalt. In Eighteenth Annual International Conference on Pavement Engineering, Asphalt Technology and Infrastructure, Liverpool, England, United Kingdom. 